\title{
Effect of Work Environment on Presenteeism among Aging American Workers: The Moderated Mediating Effect of Cynical Hostility
}

\author{
Jianwei Deng ${ }^{1,2} \oplus$, Zhennan $W u^{1,2}$, Tianan Yang ${ }^{1,2} \oplus$, Yunfei Cao ${ }^{1,2,3}$ and Zhenjiao Chen ${ }^{1,2, *}$ \\ 1 School of Management and Economics, Beijing Institute of Technology, Beijing 100081, China; \\ 111605@bit.edu.cn (J.D.); 1120171132@bit.edu.cn (Z.W.); tianan.yang@bit.edu.cn (T.Y.); \\ caoyunfei1986@bit.edu.cn (Y.C.) \\ 2 Sustainable Development Research Institute for Economy and Society of Beijing, Beijing 100081, China \\ 3 Center for Energy and Environmental Policy Research, Beijing Institute of Technology, Beijing 100081, China \\ * Correspondence: sharon2009@bit.edu.cn; Tel.: +86-010-6891-4189
}

Received: 31 May 2020; Accepted: 29 June 2020; Published: 1 July 2020

\begin{abstract}
Cynical hostility in the workplace has been studied. However, there is still no complete study examining how cynical hostility affects work performance. We examined how work environment impacts presenteeism through the mediation of cynical hostility and how chronic work discrimination moderates the relationship between work environment and cynical hostility among ageing workforces. The psychosocial vulnerability model supplies theoretical support for our model. We analyzed data from a sample of 2926 aging workforces from the Health and Retirement Study. Structural equation modeling (SEM) was used to examine the relationships with a moderated mediation model. In the final SEM model, our results showed that work environment was directly negatively associated with presenteeism. Moreover, cynical hostility was significantly inversely correlated with work environment and positively correlated with presenteeism. We found that the significant indirect effect between work environment and presenteeism can be significantly mediated by cynical hostility. In addition, cynical hostility is more likely to be affected by work environment among ageing workforces with lower levels of chronic work discrimination than those with higher levels. Enterprise, government, and employees themselves should be aware of the impact of presenteeism on ageing workforces with high levels of cynical hostility.
\end{abstract}

Keywords: cynical hostility; chronic work discrimination; work environment; presenteeism

\section{Introduction}

Cynical hostility, which manifests as a tendency to mistrust and antagonize others, is considered to be a risk factor for many health problems [1], particularly an increased risk of age-related disease [2,3]. Furthermore, it is regarded as a related factor for fatal diseases such as hypertension and coronary heart disease (CHD) and is a hotspot for health research [4,5]. Over the last 30 years, numerous studies have provided evidence to support the conclusion that cynical hostility, as measured by the Cook Medley Hostility (Ho) scale, is a psychosocial risk factor for death, medically-related disability, and ill-health [6-8]. Considerable research has been performed to uncover the mediating biopsychosocial mechanisms or processes through which hostility impacts health outcomes. Hostile individuals tend to perceive daily life experiences as more threatening and adopt inefficient coping strategies when faced with stressful situations [3]. With a deeper understanding gained from research on cynical hostility, the academic community began to explore the impact of cynical hostility on employees' work performance [9]. Research suggests that anger and hostility are positively related to counterproductive behaviors [10]. This indicates that, although cynical hostility 
is a major problem for enterprises, it may be possible to control it to some extent in order to find a solution. Chronic hostility endangers the health of employees, contributes to poor health, and leads to presenteeism or working with illness, which leads to a lower work efficiency. On the other hand, people with high cynicism and hostility tend to be resentful, suspicious, and distrustful of others. Such individuals are often under greater pressure in their interpersonal interactions. Many studies have shown that individuals with high levels of cynicism and hostility have often cultivated social support and higher levels of interpersonal conflict [3,11-13]. At the same time, the level of social support can influence proneness to violence, which is an important pressure in the workplace [14]. Many health conditions are associated with a loss of on-the-job productivity, and presenteeism is a major component of the total employer cost of these conditions. Presenteeism can be understood as the loss of productivity that occurs when employees attend work but work below their full capacity due to health problems [15]. In the United States, the cost of presenteeism in the work place has accounted for $62 \%$ of total expenditures of employees' salaries since 2000, while those of medical treatment and presenteeism have accounted for $24 \%$ and $6 \%$, respectively [16]. As a result, cynical hostility may increase the occurrence of presenteeism among employees, which is an important consideration for companies. Carrying out relevant studies will help to promote research into cynical hostility in the workplace and explore the relationship between cynical hostility and employees' work output.

Past research showed that work-related factors were important contributors to presenteeism [17,18], and a reduction in labor productivity was also caused by the work environment [19]. The work environment can not only directly affect employee presenteeism $[20,21]$ but may also indirectly affect presenteeism by influencing cynical hostility. The transactional hypothesis holds that personality and social environment are mutually determined in the short and long term [22,23]. Studies have shown that experiences in childhood and a community living environment can lead to cynical hostility [24]. At present, in addition to family and community, workplaces also determine the long-term activities of working people. Work environments have become environments that staff must face and adapt to. Aging workers often have rich working experiences, have experienced many short-term work events, and have been in a specific work environment for a long time. Their personality (such as being cynically hostile) may also change in their work environment. Therefore, we hypothesized that work environment would affect presenteeism, and cynical hostility may mediate the influence of work environment on presenteeism.

Employment discrimination has proven to be an important risk factor for mental illness among American workers $[13,25]$, and work environment is one important source of pressure. Published reports show that in the workplace, an increase in perceived age discrimination of aging workforces often results in negative feelings [26]. Hiscox, the international specialist insurer, released its 2019 Hiscox Ageism in the Workplace Study ${ }^{\mathrm{TM}}$, which revealed that $21 \%$ of US workers age 40 and older have experienced discrimination in the workplace due to their age, and respondents believe they're most likely to experience it at age 51 [27]. Many studies on race and work have linked work pressure with discrimination experienced in the workplace. This has been shown to affect a person's sense of control in their work environment, as well as their workload and career development opportunities, and induce stress [28]. Discrimination, which harms mental health, is one of the methods of measuring the main experience of unfair treatment [29]. Therefore, if workers are subjected to high levels of discrimination due to gender, race, or other traits, even if the work environment is safe and the pressure is not great, it may lead to a greater psychological burden and hostility towards others. Regarding aging workforces, companies often value younger employees because they may believe they can make a greater contribution to the company as they may have more energy and time. An increase in perceived age discrimination among aging workforces often results in negative feelings [26]. Based on the results of previous studies, this paper explored the impact of work environment on presenteeism from the perspective of cynical hostility and chronic work discrimination. We hypothesize that chronic work discrimination can moderate the impact of work environments on cynical hostility. 
Psychosocial vulnerability models represent stress vulnerability frameworks, which assume that highly hostile people are at higher risk of health problems because they have experienced relatively stressful events and have faced demands from health protection resources [5] This model has been widely used in the field of psychology and health. Many researchers have applied it to the study of the relationship between hostility and social support, as well as the influencing factors of health. Some have verified the ways and means by which hostility influences health from various perspectives [5,30-32]. By increasing stress and reducing supportive factors, cynical hostility creates a psychosocial characteristic that has a negative impact on individuals and makes them more susceptible to disease. Hostile individuals are more vulnerable after exposure to stress factors such as organizational redundancy, job insecurity, and stressful psychosocial work environments. The model creates a connection of psychosocial variables and health outcomes. If people suffer from work discrimination and their work environment does not address these issues, their level of cynical hostility may change, which may affect their rate of presenteeism. According to the social psychological vulnerability model and the transactional hypothesis, we can speculate that in different work environments, the psychological level of personal hostility is also different. This process is regulated by work discrimination, which affects the presenteeism of employees.

Older adults tend to have higher hostility scores than those who are middle-aged [33]. The relationship between aging and cynical hostility is strong and, at the same time, the global aging trend is becoming more and more serious. The British Broadcasting Corporation reported recently that by the end of 2018, the global population over 65 years old was approximately 705 million. Data from the World Population Prospects: 2019 Highlights showed that by 2050, 1 in 6 people in the world will be over 65 years old (16\%), compared with 1 in 11 people in 2019 (9\%); by 2050, 1 in 4 people in Europe and North America will be 65 years old or older. In 2018, the world's population aged 65 or over exceeded the number of people under 5 years old, unprecedentedly. In addition, the population aged 80 or over is expected to double, from 143 million in 2019 to 426 million in 2050 [34]. At present, aging trends in the world are increasing, and the labor force will be in short supply. As a result, meeting the demands of productivity becomes more difficult. Delaying the retirement age has become an important measure to supplement the level of the labor force. The UK has proposed to postpone the retirement age to 69 years old, and this means that aging workforces are worthy of even more attention. Using limited staff to create sufficient job performance affects the future development of enterprises and the stability of an aging society. Employment of aging workforces is part of what the Sustainable Development Goals focuses on [35]. However, older workers have a difference in energy, emotional needs, and room for advancement compared with younger workers. If we wish for people of retirement age to get the most out of their work, we need to care more about them as a unique group of people, including having discussions about how to improve their performance by creating an appropriate work environment. The focus should now be on paying attention to the influence of work environment on cynicism and on work ability.

We used data from the health and retirement research website (HRS), a large national group research website on the life of the aging workforces in the United States, in order to study the relationship between the four variables under the aging trend, find an effective path for affecting productivity, and provide methods for interventions in labor output. Aging populations are trending globally and, since the United States is one country with a greatly aging population, it is more representative to study the factors affecting the productivity of the aging labor force in America. The HRS survey has been conducted every two years, and the website has high credibility and strong authority. The US has one of the highest workforce participation rates for people over 65, with some of the strongest anti-discrimination laws and enforcement efforts. Aging workforces in America are common, which makes the research based on American data meaningful. At the same time, cynical hostility is closely related to aging. Consequently, its effect is more visible in this research population. Furthermore, the population data of the HRS corresponds well with improving retirement age and working ability. Generally speaking, under the global trend, the degree of aging in the United 
States is high and has strong representativeness. The HRS has a mature and credible scale and has carried out near-perfect data collection. Therefore, the results based on data analysis of the website were valuable and worthy to be widely used for reference.

We have proposed a model, as shown in Figure 1, in which cynical hostility and work environment can affect presenteeism in aging workforces, and chronic work discrimination played a moderating role. As shown in Figure 1, we hypothesize that work environment has direct effects on presenteeism, which was noted in previous studies, and has an indirect effect through cynical hostility. Also, we hypothesize that when chronic work discrimination exists, the effect of work environment on cynical hostility will be moderated.

Hypothesis 1: work environment will directly affect presenteeism.

Hypothesis 2: cynical hostility may mediate the influence of work environment on presenteeism.

Hypothesis 3: chronic work discrimination can moderate the impact of work environment on cynical hostility.

Based on this study, we provide suggestions for enterprises and governments in countries with an aging population to improve working efficiency and job satisfaction in the workforce.

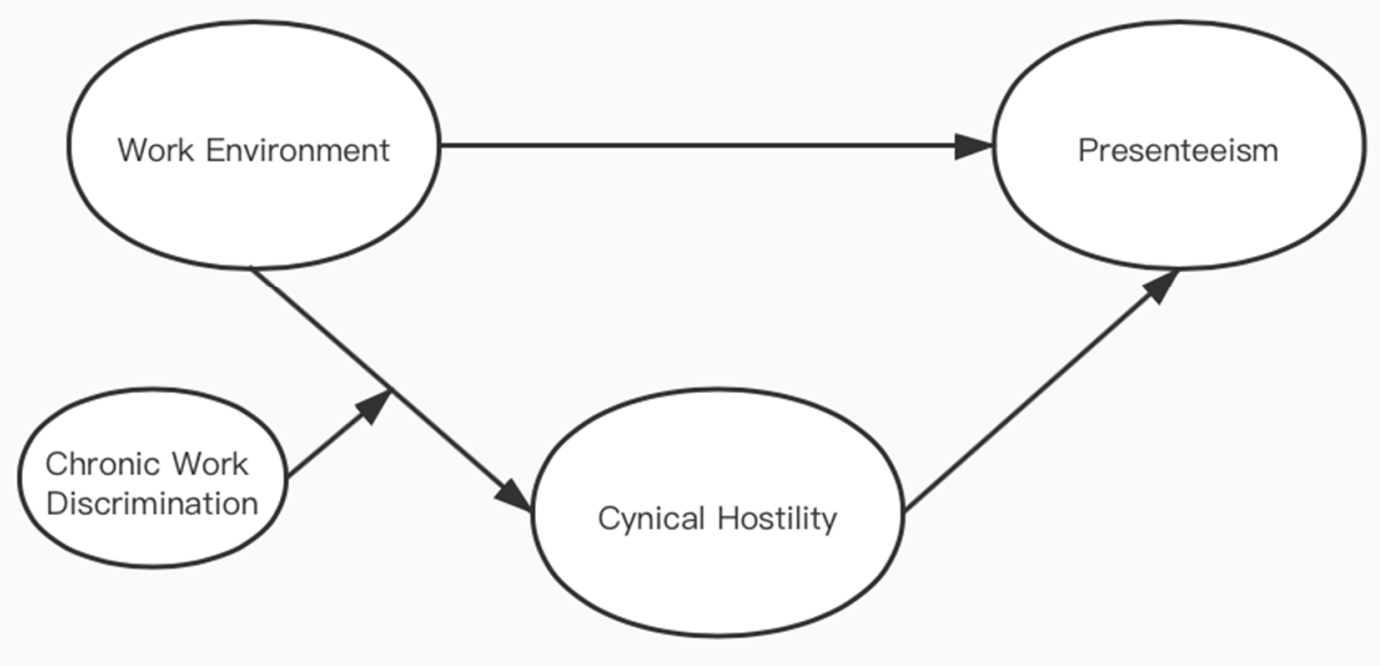

Figure 1. Proposed model of the relationship between work environment, presenteeism, and cynical hostility shows the effect of mediator resources, with chronic work discrimination as moderators.

This study primarily focuses on the group of aging workforces. In one respect, we combine the variable of personality with work and attempt to provide supplementary evidence for the variables that influence cynical hostility. We also provide reference for related follow-up research, which should be performed. In another respect, this study aims to address management problems and emphasize the practical value and empirical contribution that can be made as global aging leads to labor shortages and aging workforces. This study may provide evidence for people in countries facing such challenges. For governments, more appropriate policies can help combat shortages in the workforce. For enterprises, it is possible to improve the quality of employees' work output and enable limited workforces to contribute more to the company. Finally, by reducing cynical hostility in work environments and improving the working ability and performance of aging staff, aging workforces can be valued more and generate greater incomes that reflect their abilities. 


\section{Materials and Methods}

\subsection{Sample}

In order to explore the presenteeism mechanism of aging workers in the United States, this study used data from the University of Michigan Health and Retirement Research (HRS) in 2010, which is a large national group research website focusing on the lives of the aging workforces in the United States. All files are available to any registered users via on the website (http://hrsonline.isr.umich. edu/index.php? $p=a v a i l)$. We did not include any sensitive health data products in the Health and Retirement Survey. Aging is a global trend, and the United States is a country with a heavily aging population. The HRS survey is conducted every two years, supported by the National Institute of Aging (NIA u01ag009740) and the social security administration. HRS explores changes in labor force participation and the healthy transformation of individuals in their coming retirement and later years. The website has high credibility, large research samples, and strong authority. We used the Leave-Behind questionnaire data package for analysis. Our study was aimed at the working aging population, so we used the variable of whether they were working before analyzing the data of 2926 questionnaires. There were 1282 men in the sample, accounting for $43.8 \%$ of the total sample, and 1644 women, accounting for $56.2 \%$. There were 251 people under the age of $50(8.6 \%$ of the total sample), 1573 people aged $51-60(53.8 \%), 808$ people aged $61-70(27.6 \%), 261$ people aged $71-80(8.9 \%)$, and only 33 people aged over 80 (1.1\%). According to this data, the socioeconomic status showed: 11 people at stage $1(0.4 \%)$, which was the lowest; 23 people at stage $2(0.8 \%) ; 76$ people at stage $3(2.6 \%)$; 218 people at stage $4(7.5 \%) ; 335$ people at stage $5(11.4 \%)$; 539 people at stage $6(18.4 \%) ; 897$ people at stage $7(30.6 \%) ; 630$ people at stage $8(21.5 \%) ; 163$ people at stage $9(5.6 \%)$; and 34 people at stage 10 $(1.2 \%)$, which was the highest. There were 1929 people who were married $(65.9 \%), 14$ people who were married but whose spouse was absent (2 in institutions, 12 not in institutions, $0.5 \%), 508$ divorced or separated (17.4\%), 169 widowed (5.8\%) and 180 never married $(6.2 \%)$.

\subsection{Measures}

Presenteeism was measured using the perceived ability to work scale (PAWS) [36]. It comprises four subjective items and asks participants to rate their perceived ability on a scale of 0 to $10(0=$ simply unable to do the current job; $10=$ current working ability is at its best; Cronbach $\alpha=0.88$ ). To ensure that scores reflected the magnitude of presenteeism, we changed the directionality of scores by subtracting the original PAWS scores from 10. Thus, higher values indicate greater presenteeism [37].

Work environment was measured with the Likert scale $(1=$ strongly disagree, $2=$ disagree, $3=$ agree, $4=$ strongly agree, $5=$ does not apply; Cronbach $\alpha=0.68)$ from the social census conducted by the national anti-discrimination commission in 2002. Item 1 was reverse coded, and all responses of 5 were recoded as missing. Thus, higher values indicate a better work environment.

Cynical hostility with six items $(1=$ strongly disagree, $2=$ somewhat disagree, $3=$ slightly disagree, $4=$ slightly agree, $5=$ somewhat agree, $6=$ strongly agree; Cronbach $\alpha=0.80$ ) from the Cook-Medley Hostility Inventory $[1,38]$ has been used in several important studies evaluating the potential health consequences of hostility. We created an index of cynical hostility by averaging the scores across all items.

Six items were designed to assess chronic discrimination experienced at work. We created an index of perceived work discrimination by averaging the scores across all items (range 1-6, $\alpha=0.81$ ) [39]. Higher values indicate a more severe level of work discrimination.

\subsection{Statistical Analysis}

Data preparation and all statistical analysis, including descriptive statistics and path analysis, were conducted using SPSS 25 (IBM Corp.: Armonk, NY, USA) and Amos 21 (IBM Corp.: Armonk, NY, USA). We performed descriptive statistical analysis of the demographic variables, such as age and gender, of the sample population. Then, the missing values of the sample data were analyzed, 
and the maximum likelihood expectation method (E-M) was used to complete this. Next, the Pearson correlation test was used to check the significance of the correlation between the study variables. Then, we conducted an analysis of how gender and socioeconomic status effected cynical hostility with Cohen's d. After testing the mediating effect of the model with the structure equation model (SEM), a moderated mediating model was established and tested when it was determined that there was an intermediary effect between work environment and presenteeism.

SEM represents a series of powerful and flexible statistical techniques, which are used to examine complex research problems. It is an indispensable statistical tool for clinical researchers [40,41]. SEM has potential advantages in analyzing the path graph of potential variables with multiple indicators. In order to determine whether cynical hostility has an indirect effect on the relationship between work environment and recessive presenteeism in this study, we used maximum likelihood estimation $[42,43]$ to test the mediating effect in our initial model. The local fit of the model was assessed on the basis of the following criteria: factor reliability values of 0.6 or more, indicator reliability values of 0.3 or more for each indicator of an underlying latent variable, $p<0.05$ for all factor loadings, a root mean square error (RMSEA) less than 0.08 , the goodness of fit, norm fitting, comparative fitting index (CFI), and tucker Lewis index (TFI) of 0.90 or higher [44]. These indicators were used to test the fitting degree of the model in previous studies [45].

A nonparametric resampling procedure was used to assess mediation with SPSS INDIRECT Macros. This bootstrapping technique is a powerful method for generating confidence intervals for indirect effects, which were defined as mediating when they were significant and the confidence interval did not include zero [46]. When an effective mediation was established, we tested whether the mediation effect was related to the level of adjustment variables according to [47]. When constructing the confidence interval, at least 1000 bootstrap samples should be used to accurately adjust the upper and lower limits of a $95 \%$ confidence interval [48]. In this study, 5000 bootstrap samples were used to test the moderated mediating model to determine whether the level of a moderated variable was important.

\section{Results}

\subsection{Preliminary Analysis}

The descriptive statistics of latent variable measurement items are shown in Table 1 (PAW was not converted to recessive presenteeism). The missing values for the work environment scale were less than $30 \%$, and the E-M method could still be used to complete them. Before the structural model equation was verified, correlation analysis showed that the model fit well with the data. The relationships among the latent variables (presenteeism was formed by PAW processing) are shown below: cynical hostility $(\mathrm{M}=2.97, \mathrm{SD}=1.10)$ was positively correlated with chronic work discrimination $(r=0.25)$ and presenteeism $(r=0.15)$, and negatively correlated with work environment $(r=-0.24)$. Chronic work discrimination $(\mathrm{M}=1.74, \mathrm{SD}=0.92)$ was negatively correlated with work environment $(r=-0.49)$, positively correlated with presenteeism $(r=0.16)$, and work environment $(M=3.00, S D=$ $0.50)$ was negatively correlated with presenteeism $(\mathrm{M}=1.40, \mathrm{SD}=1.52, \mathrm{r}=-0.23)$. All correlations were significant under the 0.01 level two-tailed test. It was preliminarily concluded that there was correlation among the variables.

The independent samples t-test was calculated to examine if there were differences in cynical hostility between women and men. The result showed that the cynical hostility of men $(\mathrm{M}=3.15$, $\mathrm{SD}=1.095)$ was significantly different to that of women $(\mathrm{M}=2.83, \mathrm{SD}=1.078, p<0.001)$. The effect size was small (Cohen's $d=-0.29$ ). The result of a one-way ANOVA showed that cynical hostility among different groups divided by the socioeconomic stage was significantly different $(p<0.001)$. Bonferroni for multiple comparisons showed that the groups between stage 1 and 2,1 and 3,1 and 6,1 and 7,1 and 8,1 and 9,1 and 10,2 and 9, 3 and 9,4 and 6,4 and 6,4 and 7,4 and 8,4 and 9,5 and 6,5 and 7,5 and 8,5 and 9,6 and 8,6 and 9 , and 7 and 8 differed significantly in terms of cynical hostility $(p<0.05)$. 
Table 1. Means, SD, Missing for items.

\begin{tabular}{|c|c|c|c|c|c|c|}
\hline \multirow{2}{*}{ Variables } & \multirow{2}{*}{ Items } & \multirow{2}{*}{ Number of Cases } & \multirow{2}{*}{ Mean } & \multirow{2}{*}{ SD } & \multicolumn{2}{|c|}{ Missing } \\
\hline & & & & & Frequency & Percentage \\
\hline \multirow{5}{*}{ Cynical Hostility } & 1. Most people dislike putting themselves out to help other people. & 2841 & 3.32 & 1.466 & 85 & 2.9 \\
\hline & $\begin{array}{l}\text { 2. Most people will use somewhat unfair means to gain profit or an advantage } \\
\text { rather than lose it. }\end{array}$ & 2828 & 3.45 & 1.506 & 98 & 3.3 \\
\hline & 3. No one cares much what happens to you. & 2842 & 2.09 & 1.430 & 84 & 2.9 \\
\hline & 4. I think most people would lie in order to get ahead. & 2900 & 3.42 & 1.512 & 26 & 0.9 \\
\hline & $\begin{array}{l}\text { 5. I commonly wonder what hidden reasons another person may have for doing } \\
\text { something nice for me. }\end{array}$ & 2883 & 2.54 & 1.482 & 43 & 1.5 \\
\hline \multirow{4}{*}{$\begin{array}{l}\text { Perceived Ability } \\
\text { to Work }\end{array}$} & 1. How many points would you give your current ability to work? & 2864 & 8.63 & 1.492 & 62 & 2.1 \\
\hline & $\begin{array}{l}\text { 2. Thinking about the physical demands of your job, how do you rate your current } \\
\text { ability to meet those demands? }\end{array}$ & 2876 & 8.72 & 1.536 & 50 & 1.7 \\
\hline & $\begin{array}{l}\text { 3. Thinking about the mental demands of your job, how do you rate your current } \\
\text { ability to meet those demands? }\end{array}$ & 2879 & 8.89 & 1.314 & 47 & 1.6 \\
\hline & $\begin{array}{l}\text { 4. Thinking about the interpersonal demands of your job, how do you rate your } \\
\text { current ability to meet those demands? }\end{array}$ & 2859 & 8.73 & 1.420 & 67 & 2.3 \\
\hline \multirow{6}{*}{$\begin{array}{l}\text { Chronic Work } \\
\text { Discrimination }\end{array}$} & 1. How often are you UNFAIRLY given tasks at work that no one else wants to do? & 2881 & 2.12 & 1.475 & 45 & 1.5 \\
\hline & 2. How often are you watched more closely than others? & 2873 & 1.72 & 1.321 & 53 & 1.8 \\
\hline & $\begin{array}{l}\text { 3. How often are you bothered by your supervisor or coworkers making slurs or } \\
\text { jokes about women or racial or ethnic groups? }\end{array}$ & 2870 & 1.39 & .956 & 56 & 1.9 \\
\hline & 4. How often do you feel that you have to work twice as hard as others at work? & 2871 & 2.10 & 1.653 & 55 & 1.9 \\
\hline & 5. How often do you feel that you are ignored or not taken seriously by your boss? & 2870 & 1.78 & 1.351 & 56 & 1.9 \\
\hline & 6. How often have you been unfairly humiliated in front of others at work? & 2875 & 1.30 & 0.772 & 51 & 1.7 \\
\hline \multirow{5}{*}{ Work Environment } & 1. I have too much work to do everything well. & 2876 & 2.07 & 0.960 & 50 & 1.7 \\
\hline & 2. I have a lot to say about what happens in my job. & 2868 & 2.94 & 1.000 & 58 & 2.0 \\
\hline & 3. Promotions are handled fairly. & 2855 & 3.33 & 1.225 & 71 & 2.5 \\
\hline & $\begin{array}{l}\text { 4. I have the training opportunities I need to perform my job safely and } \\
\text { competently. }\end{array}$ & 2862 & 3.40 & 0.839 & 64 & 2.2 \\
\hline & 5. The people I work with can be relied on when I need help. & 2866 & 3.30 & 0.793 & 60 & 2.1 \\
\hline
\end{tabular}


Mediation analysis with model 4 of the PROCESS macro in SPSS was used to determine whether cynical hostility constraints mediated the association between work environment and presenteeism. This powerful bootstrapping technique yielded confidence intervals for indirect effects. A significant indirect effect and mediation were considered present when the confidence interval did not include zero. Considering the important effect marital status, gender, and socioeconomic status may have, we put the three variables as control variables. The direct effect of work environment on presenteeism was significant (point estimate for direct effect $-0.5839, \mathrm{SE}$ (standard error) $=0.0576,95 \% \mathrm{BCa} C \mathrm{CI}$ (Bias-corrected and accelerated confidence interval) $=-0.6968,-0.4710$ ). Hypothesis 1 was supported. Work environment was related to lower cynical hostility, which in turn was related to lower presenteeism (point estimate for indirect effect $=-0.0543, \mathrm{SE}=0.0141,95 \% \mathrm{BCa} C \mathrm{I}=-0.0841,-0.0284$ ).

\subsection{SEM Model}

SEM is an important statistical tool used to investigate mediation [49]. SEM was used to detect the intermediary role of cynicism in the influence of work environment on presenteeism. The indices for this initial model indicated that the model did not have acceptable fit. The indicators with low reliabilities $(<0.3)$ were deleted from the model. These modifications resulted in a measurement model with an acceptable fit (see Table 2). Analysis of the measurement model showed that our model fit the data well. In the final model, the fitness criteria indicated that the final model was appropriate (Figure 2 ). Work environment was directly inversely associated with presenteeism $(\beta=-0.22, \mathrm{SE}=0.081 ; p<0.01)$ and cynical hostility $(\beta=-0.20, \mathrm{SE}=0.057 ; p<0.01)$. There was a significant positive association between cynical hostility and presenteeism $(\beta=0.08, \mathrm{SE}=0.032 ; p<0.01)$. Work environment explained $8 \%$ of the variability in cynical hostility. Work environment and cynical hostility explained $7 \%$ of variability in presenteeism. Hypothesis 2 was supported.

Table 2. Measures of global fit for all models.

\begin{tabular}{ccccccc}
\hline Model Description & $\mathbf{C h i}^{\mathbf{2}}$ & df & RMSEA (90\% CI) & GIF & CFI & TLI \\
\hline Thresholds for acceptable fit & & & $<0.06$ & $\geq 0.90$ & $\geq 0.90$ & $\geq 0.90$ \\
$\begin{array}{c}\text { Baseline model V1 } \\
\text { Model V2 excludes low }\end{array}$ & 911.069 & 74 & $0.062(0.059,0.066)$ & 0.955 & 0.939 & 0.926 \\
indicator reliability $(<0.3)$ & 448.320 & 60 & $0.047(0.043,0.051)$ & 0.976 & 0.971 & 0.963 \\
\hline
\end{tabular}

RMSEA: root mean square error of approximation; GFI: Goodness of Fit Index; CFI: Comparative Fit Index; TLI: Tucker-Lewis index.

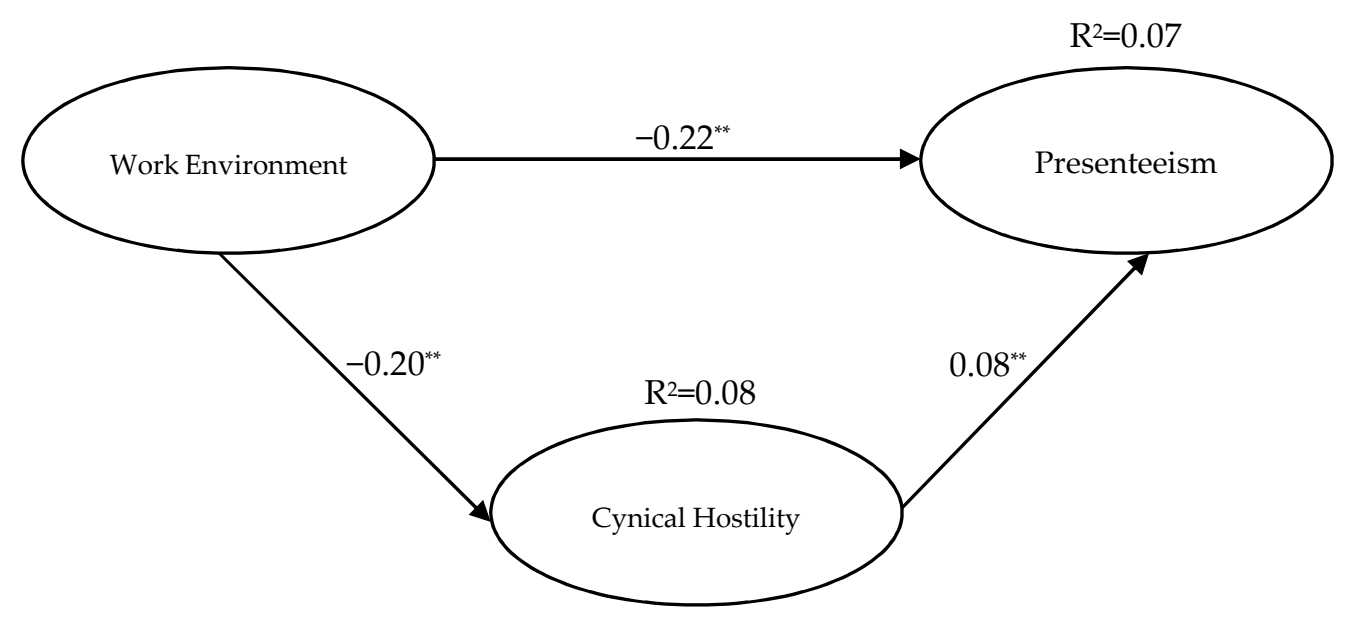

Figure 2. Mediator model of how work environment affects presenteeism. The numbers in the path are standardized regression coefficients and the variables show variability, namely, root mean square error of approximation $=0.047$, goodness-of-fit index $=0.976$, comparative fit index $=0.971$, Tucker Lewis index $=0.963 ;{ }^{* *} p<0.01 ; \mathrm{R}^{2}$, and the percentage of the variability in cynical hostility or presenteeism. 


\subsection{Moderated Mediation Analysis}

On the basis of significant results in mediation models and theoretical considerations, we used SPSS PROCESS Macros Model 7 to determine whether, how, and under what conditions a given effect occurs in relation to the moderating role of chronic work discrimination (Figure 1).

Table 3 shows the results of inputting cynical hostility into the model. PROCESS model 7 was tested with presenteeism as the result variable. The product of work environment and chronic work discrimination had a significant predictive effect on cynical hostility $(p<0.01, \beta=0.11)$. The specific indirect effects and standard errors under different values of chronic work discrimination are shown in Table 3. Chronic work discrimination significantly moderates the indirect effect of work environment on presenteeism. The interaction between chronic work discrimination and work environment decreased from a lower to higher level. The effect on cynical hostility was strongest when chronic job discrimination was lowest, which further led to the strongest disincentive to implicit presenteeism (see Table 3). Hypothesis 3 was supported.

Table 3. Conditional indirect effect(s) of work environment (WE) on presenteeism (Pre) at values of the moderator(s) up to a level of $95 \%$.

\begin{tabular}{cccccc}
\hline \multicolumn{2}{c}{ Variable } & \multicolumn{4}{c}{ BC 5000 BOOT } \\
\hline \multirow{2}{*}{ Chronic Work Discrimination } & \multicolumn{4}{c}{ Cynical Hostility } \\
\cline { 3 - 6 } & & IND & SE & LL95 & UL95 \\
\hline Low & 0.08 & -0.05 & 0.01 & -0.0769 & -0.0239 \\
Mean & 1.74 & -0.04 & 0.01 & -0.0585 & -0.0186 \\
High & 2.65 & -0.02 & 0.01 & -0.0473 & -0.0105 \\
\hline
\end{tabular}

Coefficients represent specific indirect effects and standard errors at different values of chronic work discrimination, and the lower and upper bounds of $95 \%$ BC bootstrap confidence intervals for that effect, with 5000 bootstrap samples. Low signifies values at $1 \mathrm{SD}$ below the mean, mean signifies values at the mean, and high signifies values at 1 SD above the mean. IND: indirect effects.

\section{Discussion}

This study extended the psychological variable of cynical hostility to the empirical study of the workplace. We investigated the influence of work environment on presenteeism and the mediating effect of cynical hostility on this effect, and we also put chronic work discrimination into the model to explore how this variable moderates the relationship between work environment and cynical hostility. The results showed that work environment has a direct negative impact on presenteeism, and cynical hostility mediates the relationship between them. Work environment and cynical hostility showed a negative relationship, that is, a poor work environment induces higher cynical hostility. There was a positive relationship between cynical hostility and presenteeism, that is to say, higher cynical hostility produced a higher level of presenteeism. In addition, we also found that chronic work discrimination significantly reversed the influence of work environment on cynical hostility. The mediating effect of cynical hostility was relatively small for those with a high chronic work discrimination rate.

Work environment may restrain cynical hostility. It has been shown that the environment has a certain impact on people's mental health. For example, the social environment between neighbors affects the psychological and social functions of adults [50]. In one study, it was found that a lower amount of social support led to a higher amount of cynical hostility [51]. Our results showed that the better the environment was, the lower cynical hostility became. The level of cynicism and hostility can also be influenced by the work environment that people are exposed to for a long time, in addition to the community. When people perceive an unfriendly environment and interpersonal frustration, their distrust and hostility towards others will increase. As an antecedent of the model, this relationship has been further confirmed. In an unfriendly environment, older people will lose the necessary social support and form negative psychological emotions. This should encourage enterprises to pay attention to the work environment of their aged employees, give them appropriate workloads, and allow 
them to feel that the working atmosphere is welcoming. More than that, giving employees equal opportunities for promotion and training, as well as cultivating the company's "home culture", can help to form a good working atmosphere, effectively improve the employees' mentality, and consequently improve productivity.

Cynical hostility might mediate the relationships between work environment and presenteeism. Cynical hostility has always been defined as a persistent, negative attitude towards others involving cognitive, emotional, and behavioral components [52]. Studies have proven that higher levels of cynical hostility are harmful to health [53-55]. The perception of high-intensity work may lead to distrust and cynicism in employees, which may lead to mental health problems [56], but it has not yet been related to work output. This study focused on the results of cynical hostility in the workplace. According to the social vulnerability theory, people with high levels of cynical hostility will feel more pressure and increase their presenteeism at work. The transactional hypothesis provides theoretical support for the relationship between work environment and cynical hostility. Therefore, we took cynical hostility as the mediator variable between work environment and presenteeism. This was verified in the empirical study and then supported the outcome variable of cynical hostility. Presenteeism should have more attention paid to it, especially in the aging workforces. An optimistic attitude is an important aspect of healthy aging [57]. With the increase of age, the metabolic burden of cynical hostility in the middle-aged and elderly is heavier [58], and the current trend of population aging is becoming more and more severe. According to the world bank database, in 2019, the population aged over 65 in the United States was as high as 15\% [34]. This shows that between 1977 and 2007, the number of employees aged 65 and over increased by 101\%, among which the number of men increased by $75 \%$ and that of women nearly tripled. According to Gary Burtless, an economic researcher at the Brookings Institution, since the 1990s, more and more Americans have delayed their retirement for two reasons: one is the delay in the age of receiving social security benefits, and the other is the cancellation or reduction of pension benefits by employers, meaning that employees are unable to retire [59]. Using more aging labor in the workforce will be an important measure when dealing with the aging population. Therefore, enterprises should pay attention to the productivity of their aging workforces. Optimizing the work environment and paying close attention to and controlling the degree of cynical hostility in employees will reduce the probability of events that promote the occurrence of cynical hostility, thus making the aged population work more healthily and actively. With more training and working experience, the aging population in a company is usually more familiar with the work content, and their work skills are further strengthened. If their normal work can be continued and presenteeism can be reduced, they will greatly improve the performance of the company. Aging workforces should pay more attention to their own status in order to reduce cynical hostility in themselves and make themselves more valued.

With the increase of chronic work discrimination, the inhibition effect of work environment on cynicism will be weakened, and the intermediary effect of cynicism will be weakened. Cynical hostility is a psychological variable. Studies have shown that discrimination damages health by increasing cynical hostility [60]. Therefore, we introduced a moderating variable into the model and found that chronic work discrimination has a negative correlation with the work environment, which promotes the cynicism hostility and has a negative moderating effect on the work environment. This means that when the frequency of chronic work discrimination is high and the working environment is not very good, the cynical hostility of employees will seriously increase, leading to a wider range of hidden presenteeisms. With the increase in employees' age, if many enterprises only pay attention to the treatment of young employees and discriminate against the decline of physical functions and working conditions of aging workforces to a certain extent, the weakening effect that working environment may have on cynicism will be reduced. Therefore, enterprises should form preferential treatment policies for their older employees or create corresponding employee care plans to show respect for the older employees. These can enhance employees' sense of work environment identity, reduce the degree of hostility in social relations, and increase necessary rewards for their working abilities with a more 
optimistic attitude. The government may also pay attention to the phenomenon of discrimination in the workplace and introduce relevant laws and policies to improve the situation.

Working environments might affect the presenteeism of the aging workforces. Previously, some scholars proposed that work stress would affect presenteeism [61]. Work pressure is a part of the work environment. This study explored the relationship between work pressure and presenteeism in the aspect of the demands on the aging workforces. The results showed that work environment has an inhibitory effect on recessive presenteeism (i.e., a better environment can effectively reduce presenteeism). This result also verifies the conclusion of Yang [44], which is enterprises paying attention to improving their work environment can effectively avoid the occurrence of anti-productivity behavior from aging chemical authors and provide a powerful means for effective intervention in presenteeism behavior of aging workers.

This paper has some limitations. Firstly, the HRS database variables used in this study were not measured continuously. The data was not available, so we used a cross-sectional study, and we did not analyze how variables changed according to time. Consequently, we could not determine a clear causal relationship among the variables. Secondly, the scale adopted in this paper was subjective judgment rather than objective behavior data. It emphasized personal feelings, which may be affected by some irrational factors. When a person is in a bad mood, they may have poor judgment on their level of hostility. There may be differences in the expression of emotions, resulting in a measurement deviation. Thirdly, the data used in this study was from the United States and aimed at the aging population in the United States. Due to cultural differences and different ideas between China and the West, there may be differences in the judgment of work environments and personal hostility levels, affecting the general applicability of the conclusions. Fourthly, there may be many other variables relating to cynical hostility that would affect the results, such as bullying, burnout, verbal violence, social support, mental health, physical health, and mental health disorders. Due to the secondary data we used, we did not take these variables under much more consideration. These variables should be considered in futures studies. Finally, since we used secondary data, the variables we want to study on are not mentioned every year, and the data cannot be available in real-time, so we had to use data from 2010, not the latest year's. There may be some differences in using the latest data.

Future research can focus on objective standards, designing longitudinal research programs for in-depth verification and taking samples from multiple countries so that more general research can be performed. If researchers are interested in cynical hostility in the workplace, finding other variables associated with it may be a direction for future research. If possible, using the latest data would be better.

\section{Conclusions}

This study showed that the work environment of aging workforces can be negatively related to the level of presenteeism, and it can indirectly affect the level of presenteeism through the mediation of cynical hostility, which is effectively negatively moderated by chronic work discrimination. Enterprises and governments should pay more attention to reducing the presenteeism of elderly employees, providing a better working environment and reducing the negative emotions of the aging workforces so as to enable limited workforces to contribute more to the company.

Author Contributions: Conceptualization, J.D. and Z.C.; Formal analysis, J.D., Z.W., T.Y., Y.C. and Z.C.; Funding acquisition, J.D., T.Y., Y.C. and Z.C.; Investigation, J.D., Z.W., T.Y., Y.C. and Z.C.; Methodology, J.D., Z.W., T.Y., Y.C. and Z.C.; Project administration, J.D. and Z.C.; Supervision, J.D. and Z.C.; Validation, J.D., Z.W., T.Y. and Z.C.; Visualization, J.D., Z.W., T.Y., Y.C. and Z.C.; Writing—original draft, J.D.; Writing-review \& editing, Z.W., T.Y., Y.C. and Z.C. All authors have read and agreed to the published version of the manuscript.

Funding: This research was funded by National Science Funding of China (grant no. 71804009, 71974011, 71972012, 91746116, 71471017, 71603018, 71601020, 71704011), Beijing Social Science Foundation (grant no. 17GLC043, 17JDGLB008), Beijing Institute of Technology Fund Program for Young Scholars (No. 3210012331705), Special Fund for Joint Development Program of Beijing Municipal Commission of Education.

Conflicts of Interest: The authors declare no conflict of interest. 


\section{References}

1. Costa, P.T.; Zonderman, A.B.; Mccrae, R.R.; Williams, R.B. Cynicism and paranoid alienation in the Cook and Medley HO scale. Psychosom. Med. 1986, 48, 283-285. [CrossRef] [PubMed]

2. Kubzansky, L.D.; Sparrow, D.; Jackson, B.; Cohen, S.; Weiss, S.T.; Wright, R.J. Angry breathing: A prospective study of hostility and lung function in the Normative Aging Study. Thorax 2006, 61, 863-868. [CrossRef] [PubMed]

3. Brydon, L.; Lin, J.; Butcher, L.; Hamer, M.; Erusalimsky, J.D.; Blackburn, E.H.; Steptoe, A. Hostility and cellular aging in men from the Whitehall II cohort. Biol. Psychiatry 2012, 71, 767-773. [CrossRef] [PubMed]

4. Smith, T.W. Hostility and health: Current status of a psychosomatic hypothesis. Health Psychol. 1992, 11, 139-150. [CrossRef]

5. Grothe, K.; Bodenlos, J.S.; Whitehead, D.; Olivier, J.; Brantley, P.J. The Psychosocial Vulnerability Model of Hostility as a Predictor of Coronary Heart Disease in Low-income African Americans. J. Clin. Psychol. Med. Settings 2008, 15, 163-169. [CrossRef]

6. Hart, K.E.; Differences, I. Cynical hostility and deficiencies in functional support: The moderating role of gender in psychosocial vulnerability to disease. Personal. Individ. Differ. 1999, 27, 69-83. [CrossRef]

7. Miller, T.Q.; Smith, T.W.; Turner, C.W.; Guijarro, M.L.; Hallet, A.J. Meta-analytic review of research on hostility and physical health. Psychol. Bull. 1996, 119, 322-348. [CrossRef]

8. Smith, T.W.; Ruiz, J.M.; Psychology, C. Psychosocial influences on the development and course of coronary heart disease: Current status and implications for research and practice. J. Consult. Clin. Psychol. 2002, 70, 548-568. [CrossRef]

9. Dong, G.; Wang, M.; Liu, X.; Liang, Q.; Du, X.; Potenza, M.N. Cue-elicited craving-related lentiform activation during gaming deprivation is associated with the emergence of Internet gaming disorder. Addict. Biol. 2020, 25, e12713. [CrossRef]

10. Judge, T.A.; Scott, B.A.; Ilies, R. Hostility, job attitudes, and workplace deviance: Test of a multilevel model. J. Appl. Psychol. 2006, 91, 126-138. [CrossRef]

11. Greenglass, E.R.; Julkunen, J.J.P.; Differences, I. Construct validity and sex differences in Cook-Medley hostility. Personal. Individ. Differ. 1989, 10, 209-218. [CrossRef]

12. Progovac, A.M.; Chang, Y.F.; Chang, C.H.; Matthews, K.A.; Donohue, J.M.; Scheier, M.F.; Habermann, E.B.; Kuller, L.H.; Goveas, J.S.; Chapman, B.P.J. Are optimism and cynical hostility associated with smoking cessation in older women? Ann. Behav. Med. 2017, 51, 500-510. [CrossRef]

13. King, K. Aggravating conditions: Cynical hostility and neighborhood ambient stressors. Soc. Sci. Med. 2012, 75, 2258-2266. [CrossRef] [PubMed]

14. Magnavita, N. Workplace violence and occupational stress in healthcare workers: A chicken-and-egg situation-results of a 6-year follow-up study. J. Nurs. Scholarsh. 2014, 46, 366-376. [CrossRef] [PubMed]

15. Mental Health at Work: Developing the Business Case. Available online: https://www.centreformentalhealth. org.uk/publications/mental-health-work-developing-business-case (accessed on 25 June 2020).

16. Hemp, P. Presenteeism: At work-But out of it. Harv. Bus. Rev. 2004, 82, 49-58. [PubMed]

17. Merrill, R.M.; Aldana, S.G.; Pope, J.E.; Anderson, D.R.; Coberley, C.R.; Whitmer, R.W.; Subcomm, H.R.S. Presenteeism according to healthy behaviors, physical health, and work environment. Popul. Health Manag. 2012, 15, 293-301. [CrossRef]

18. Hansen, C.D.; Andersen, J.H. Going ill to work-What personal circumstances, attitudes and work-related factors are associated with sickness presenteeism? Soc. Sci. Med. 2008, 67, 956-964. [CrossRef]

19. Stromberg, C.; Aboagye, E.; Hagberg, J.; Bergstrom, G.; Lohela-Karlsson, M. Estimating the effect and economic impact of absenteeism, presenteeism, and work environment-related problems on reductions in productivity from a managerial perspective. Value Health 2017, 20, 1058-1064. [CrossRef]

20. Yang, T.A.; Zhu, M.J.; Xie, X.Y. The determinants of presenteeism: A comprehensive investigation of stress-related factors at work, health, and individual factors among the aging workforce. J. Occup. Health 2016, 58, 25-35. [CrossRef]

21. McGregor, A.; Iverson, D.; Caputi, P.; Magee, C.; Ashbury, F. Relationships between work environment factors and presenteeism mediated by employees' health: A preliminary study. J. Occup. Environ. Med. 2014, 56, 1319-1324. [CrossRef] 
22. Gallo, L.C.; Smith, T.W. Patterns of hostility and social support: Conceptualizing psychosocial risk factors as characteristics of the person and the environment. J. Res. Personal. 1999, 33, 281-310. [CrossRef]

23. Kiesler, D.J. Contemporary interpersonal theory and research: Personality, psychopathology, and psychotherapy. Wiley series in clinical psychology and personality. J. Psychother. Pract. Res. 1996, 6,339 .

24. Hakulinen, C.; Jokela, M.; Hintsanen, M.; Pulkkiraback, L.; Hintsa, T.; Merjonen, P.; Josefsson, K.; Kahonen, M.; Raitakari, O.T.; Keltikangas-Järvinen, L. Childhood family factors predict developmental trajectories of hostility and anger: A prospective study from childhood into middle adulthood. Psychol. Med. 2013, 43, 2417-2426. [CrossRef] [PubMed]

25. Darity, W.A., Jr. Employment discrimination, segregation, and health. Am. J. Public Health 2003, 93, $226-231$. [CrossRef] [PubMed]

26. Poscia, A.; Moscato, U.; La Milia, D.I.; Milovanovic, S.; Stojanovic, J.; Borghini, A.; Collamati, A.; Ricciardi, W.; Magnavita, N. Workplace health promotion for older workers: A systematic literature review. BMC Health Serv. Res. 2016, 16, 329. [CrossRef]

27. 2019 Hiscox Ageism in the Workplace StudyTM. Available online: https://www.hiscox.com/documents/2019Hiscox-Ageism-Workplace-Study.pdf (accessed on 30 June 2020).

28. Bhui, K.; Stansfeld, S.; Mckenzie, K.; Karlsen, S.; Nazroo, J.; Weich, S. Racial/ethnic discrimination and common mental disorders among workers: Findings from the EMPIRIC study of ethnic minority groups in the United Kingdom? Am. J. Public Health 2005, 95, 496-501. [CrossRef]

29. Schmitt, M.T.; Branscombe, N.R.; Postmes, T.; Garcia, A. The consequences of perceived discrimination for psychological well-being: A meta-analytic review. Psychol. Bull. 2014, 140, 921-948. [CrossRef]

30. O’Neil, J.N.; Emery, C.F. Psychosocial vulnerability, hostility, and family history of coronary heart disease among male and female college students. Int. J. Behav. Med. 2002, 9, 17. [CrossRef]

31. Hart, K.E.; Hope, C.W. Cynical hostility and the psychosocial vulnerability model of disease risk: Confounding effects of neuroticism (negative affectivity) bias. Personal. Individ. Differ. 2004, 36, 1571-1582. [CrossRef]

32. Kivimäki, M.; Vahtera, J.; Koskenvuo, M.; Uutela, A.; Pentti, J. Response of hostile individuals to stressful change in their working lives: Test of a psychosocial vulnerability model. Psychol. Med. 1998, 28, 903-913. [CrossRef]

33. Barefoot, J.C.; Beckham, J.C.; Haney, T.L.; Siegler, I.C.; Lipkus, I.M. Age differences in hostility among middle-aged and older adults. Psychol. Aging 1993, 8, 3-9. [CrossRef] [PubMed]

34. United Nations. World Population Prospects 2019: Highlights. Available online: https://population.un.org/ wpp/Publications/Files/WPP2019_Highlights.pdf (accessed on 8 January 2020).

35. Sustainable Development Goal 8. Available online: https://sustainabledevelopment.un.org/sdg8 (accessed on 14 June 2020).

36. Vanni, K.J.; Virtanen, P.; Luukkaala, T.; Nygard, C.H. Relationship between perceived work ability and productivity loss. Int. J. Occup. Saf. Ergon. 2012, 18, 299-309. [CrossRef] [PubMed]

37. Ilmarinen, J.; Rantanen, J. Promotion of work ability during ageing. Am. J. Ind. Med. 1999, 36, 21-23. [CrossRef]

38. Cook, W.W.; Medley, D.M. Proposed hostility and pharisaic-virtue scales for the MMPI. J. Appl. Psychol. 1954, 38, 414-418. [CrossRef]

39. Williams, D.R.; Yu, Y.; Jackson, J.S.; Anderson, N.B. Racial differences in physical and mental health. J. Health Psychol. 1997, 2, 335-351. [CrossRef]

40. Hoyle, R.H. Introduction to the special section: Structural equation modeling in clinical research. J. Consult. Clin. Psychol. 1994, 62, 427-428. [CrossRef]

41. Maccallum, R.C.; Austin, J.T. Applications of structural equation modeling in psychological research. Annu. Rev. Psychol. 2000, 51, 201-226. [CrossRef]

42. Schumacker, R.E.; Lomax, R.G. A Beginner's Guide to Structural Equation Modeling; Lawrence Erlbaum Associates, Inc.: Mahwah, NJ, USA, 1996.

43. Anderson, J.C.; Gerbing, D.W. Structural equation modeling in practice: A review and recommended two-step approach. Psychol. Bull. 1988, 103, 411-423. [CrossRef]

44. Yang, T.; Shi, H.; Guo, Y.; Jin, X.; Liu, Y.; Gao, Y.; Deng, J. Effect of work environment on presenteeism among aging american workers: The moderated mediating effect of sense of control. Int. J. Environ. Res. Public Health 2020, 17, 245. [CrossRef] 
45. Rovniak, L.S.; Anderson, E.S.; Winett, R.A.; Medicine, R. Social cognitive determinants of physical activity in young adults: A prospective structural equation analysis. Ann. Behav. Med. 2002, 24, 149-156. [CrossRef]

46. Deng, J.; Guo, Y.; Shi, H.; Gao, Y.; Yang, T. Effect of discrimination on presenteeism among aging workers in the United States: Moderated mediation effect of positive and negative affect. Int. J. Environ. Res. Public Health 2020, 17, 1425. [CrossRef] [PubMed]

47. Hayes, A.F. Introduction to Mediation, Moderation, and Conditional Process Analysis: A Regression-Based Approach; Guilford: New York, NY, USA, 2017.

48. Edwards, J.R.; Lambert, L.S. Methods for integrating moderation and mediation: A general analytical framework using moderated path analysis. Psychol. Methods 2007, 12, 1-22. [CrossRef] [PubMed]

49. Cheung, G.W.; Lau, R.S. Testing mediation and suppression effects of latent variables: Bootstrapping with structural equation models. Organ. Res. Methods 2008, 11, 296-325. [CrossRef]

50. Everson-Rose, S.A.; Skarupski, K.A.; Barnes, L.L.; Beck, T.; Evans, D.A.; de Leon, C.F.M. Neighborhood socioeconomic conditions are associated with psychosocial functioning in older black and white adults. Health Place 2011, 17, 793-800. [CrossRef]

51. Angerer, P.; Siebert, U.; Kothny, W.; Muhlbauer, D.; Mudra, H.; Von Schacky, C. Impact of social support, cynical hostility and anger expression on progression of coronary atherosclerosis. J. Am. Coll. Cardiol. 2000, 36, 1781-1788. [CrossRef]

52. Christensen, U.; Lund, R.; Damsgaard, M.T.; Holstein, B.E.; Ditlevsen, S.; Diderichsen, F.; Due, P.; Iversen, L.; Lynch, J. Cynical hostility, socioeconomic position, health behaviors, and symptom load: A cross-sectional analysis in a Danish population-based study. Psychosom. Med. 2004, 66, 572-577. [CrossRef] [PubMed]

53. Lloydjones, D.; Adams, R.J.; Brown, T.M.; Carnethon, M.; Dai, S.; De, S.G.; Ferguson, T.B.; Ford, E.; Furie, K.; Gillespie, C. Heart disease and stroke statistics-2010 update: A report from the American Heart Association. Circulation 2010, 127, 143-152.

54. Izawa, S.; Eto, Y.; Yamada, K.C.; Nakano, M.; Yamada, H.; Nagayama, M.; Kikuchi, T.; Nomura, S. Cynical hostility, anger expression style, and acute myocardial infarction in middle-aged Japanese men. Behav. Med. 2011, 37, 81-86. [CrossRef]

55. Tindle, H.A.; Chang, Y.F.; Kuller, L.H.; Manson, J.E.; Robinson, J.G.; Rosal, M.C.; Siegle, G.J.; Matthews, K.A. Optimism, cynical hostility, and incident coronary heart disease and mortality in the women's health initiative. Circulation 2009, 120, 656-662. [CrossRef]

56. Tornroos, M.; Elovainio, M.; Keltikangasjarvinen, L.; Hintsa, T.; Pulkkiraback, L.; Hakulinen, C.; Merjonen, P.; Theorell, T.; Kivimaki, M.; Raitakari, O.T.; et al. Is there a two-way relationship between cynicism and job strain? Evidence from a prospective population-based study. J. Occup. Environ. Med. 2015, 57, 479-484. [CrossRef]

57. Steptoe, A.; Wright, C.E.; Kunzebrecht, S.R.; Iliffe, S. Dispositional optimism and health behaviour in community-dwelling older people: Associations with healthy ageing. Br. J. Health Psychol. 2006, 11, 71-84. [CrossRef] [PubMed]

58. Dantono, B.; Moskowitz, D.S.; Nigam, A. The metabolic costs of hostility in healthy adult men and women: Cross-sectional and prospective analyses. J. Psychosom. Res. 2013, 75, 262-269. [CrossRef] [PubMed]

59. News, C. World Journal: "the Silver Generation" is Becoming an Important Part of the American Labor Market. Available online: http://www.chinanews.com/hr/2019/02-20/8759386.shtml (accessed on 25 June 2020).

60. Brondolo, E.; Hausmann, L.R.M.; Jhalani, J.; Pencille, M.; Atencio-Bacayon, J.; Kumar, A.; Kwok, J.; Ullah, J.; Roth, A.; Chen, D.; et al. Dimensions of perceived racism and self-reported health: Examination of racial/ethnic differences and potential mediators. Ann. Behav. Med. 2011, 42, 14-28. [CrossRef] [PubMed]

61. Deng, J.; Li, Y.; Sun, Y.; Lei, R.; Yang, T. Public service motivation as a mediator of the relationship between job stress and presenteeism: A cross-sectional study from Chinese public hospitals. BMC Health Serv. Res. 2019, 19, 625. [CrossRef] [PubMed]

(C) 2020 by the authors. Licensee MDPI, Basel, Switzerland. This article is an open access article distributed under the terms and conditions of the Creative Commons Attribution (CC BY) license (http://creativecommons.org/licenses/by/4.0/). 